\title{
Analysis on the Moral Education Value of Picture Books
}

\author{
$\mathrm{Yu} \mathrm{Zhao}^{1, *}$ \\ ${ }^{I}$ School of Foreign Languages, Hebei Normal University, Shijiangzhuang, Hebei Province, 050000, China \\ *Corresponding author. Email: gaoming@cas-harbour.org
}

\begin{abstract}
Moral education is the top priority of quality education. Elementary school is a critical period for children to form excellent character, and the effectiveness of moral education directly affects the character building and further development of children. However, moral education at this stage in China tends to remain superficial and does not have a substantial positive impact on students' moral feelings and behaviors. Picture books, as a kind of reading material with both pictures and texts, break the traditional way of reading. The combination of illustrations and text can attract children's interest and thus trigger in-depth thinking and perception. If picture books are used as moral education materials in elementary schools with proper teaching design and education methods, the moral education effect should be obvious. The purpose of this paper is to investigate the value and effectiveness of picture books for moral education. The main research methods of this thesis are document study and the experience summary. The results of the study are as follows: 1) Picture books for teaching are effective moral education tools; 2) teachers can select picture book materials in a targeted way according to students' moral performance; 3) teaching with picture books can promote teacher-student communication, and that communication can in turn promote the effectiveness of moral education, which form a virtuous circle. Therefore, picture books should be used as a good material in the moral education of children.
\end{abstract}

Keywords: picture book, moral education, primary school, document study method

\section{INTRODUCTION}

In the stage of quality education advocating the all-round development, moral education is the top priority. National Medium and Long-Term Educational Reform and Development Program (2010-2020) points out the importance of moral education. The plasticity of primary school students is strong, since moral education should be enlightened at this time. However, currently, due to our country's primary schools do not pay much attention to moral education, its development is sometimes limited to the theoretical level. In order to truly achieve the purpose and requirements of moral education and realize its practical significance, educators need to adopt appropriate educational means and mediums to guide and penetrate with purpose.

Picture books are a form of literature that combines pictures and texts, and are often used as extra-curricular reading materials for children, and sometimes as teaching materials. However, in teaching picture books, teachers usually focus on teaching the knowledge and skills, while neglecting the educational significance of picture books. In fact, picture books have a very important educational significance, and the stories they tell are philosophical and can guide children to form some good qualities. Therefore, picture books are a good material and medium for moral education. Children will read and perceive the picture book stories autonomously, and with the teacher guiding them with appropriate teaching methods, the moral effect should be obvious.

According to the research of some researchers, since 2007, the market share of picture books has increased year by year [1]. Taking "picture books" as the key word, the author searched relevant literature from 2010 to 2020 in CNKI Chinese Journal Full-text database and Wanfang database, and found that domestic research on picture books was on the rise. In terms of the subject areas studied, research results are fruitful. Educational research related to picture books is mostly focused on early childhood teaching and elementary school level, which mainly involves the reading and teaching aspects of picture books. In Taiwan, the study of picture books 
has been conducted extensively from preschool to high school level, with life education, character education, environmental education, and gender education as the topics [2]. By using the literature analysis method, the author found that research using picture books as a way to conduct moral education is not common in mainland China. Therefore, the authors hope to explore in depth the effectiveness and value of using picture books in moral education by drawing on relevant studies from abroad and Taiwan.

\section{THE FEASIBILITY OF USING PICTURE BOOKS TO IMPLEMENT MORAL EDUCATION}

\subsection{Low recognition of the educational value of picture books in mainland China}

In China, the use of picture books for teaching is still relatively homogeneous, and is not very different in nature from the teaching of reading in various subjects. Therefore, it is difficult to realize the true educational value of a good picture book without proper guidance. Picture books were born in Europe in the 17th century. In the 1950s and 1960 s, picture books were introduced to Korea and Japan. In the late 1990s, picture books were gradually introduced to China's mainland, and until after 2010, they were spread to a large number of ordinary families. In the 21 st century, picture book reading has become the fashion of children's reading around the world. Internationally recognized: "picture books are the most suitable materials for young children to read." In a well illustrated book, the pictures are not dispensable childish elements, not appendages of the text, not illustrations of the text. The pictures and words in a picture book assume independent narrative functions [3]. Pictures can also be regarded as the life of picture books. The pictures and the words mutually integrate and narrate a story together. The educational value of a good storytelling picture book is self-evident when it is used in the right way. Taking the picture book Swimmy for example, it tells and draws the story of a group of small fish that swim as a big fish by working together to avoid predation by the big fish. It clearly reflects the theme of unity and cooperation, which has practical implications for students' collective life, such as cleaning classroom hygiene and participating in group activities at school.

However, a few years ago, a version of the elementary school language textbook incorporated the text of the picture book Swimmy into the second grade text, but removed the pictures. This completely stripped its narrative character of combining pictures and text. According to Piaget's theory of cognitive development, students in the first and second grade are still in the preoperational stage. Due to the lack of knowledge and experience, children's thinking development at this stage is concrete image. They mainly think through concrete images or representations of things [4]. For young readers, lack of the process of imagining and thinking through the pictures, the students may not even be able to understand the story. The abstract meaning of unity and cooperation is then lost in its visualized expression. In the case of misinterpretation of picture books by education departments and educators, the educational value cannot be achieved. The author believes that the root cause of all of the above is that the picture books have just been introduced to the mainland for a short time, thus lack of experts and scholars who really specialize in the study of picture books.Japanese picture book master Naoto Matsui believes that if it were not for the Sino-Japanese War, The development of Picture books in China would have been even better than in Japan [5]. The war hindered the development of Picture books in China for a longtime. Consequently, the use of picture books is not standardized from policy maker to implementer. Educators have not organized special training in picture book teaching, so the educated cannot fully perceive the core ideas of excellent picture book Therefore, we should strengthen the publicity of the educational significance of picture books, popularize the knowledge of picture books, and correct people's wrong understanding of picture books. Only in this way can we make better use of picture book resources and give full play to their real value.

\subsection{The remarkable moral effect of picture books education}

The classroom is the place to cultivate students' comprehensive quality. Making full use of class time to implement moral education is a must. Moreover, educating with the assistant of picture books can achieve twice the effect with half the effort. Elementary school students are still in the primary stage of thought enlightenment, their logical thinking, concentration, ability to distinguish right from wrong are still immature. It is easy for them to get distracted and make small movements in class, and some students even get bored with the class because it is boring. So the effect of the traditional inculcating type teaching is not obvious Furthermore, elementary school students are sensitive to stories and vivid images, so picture books just meet the preferences of elementary school students. Take students' interests as the key point to gradually guide students to moral education, fully mobilize children's enthusiasm, which can greatly stimulate the elements of moral education and cultivate the moral quality of children.

There had been experimental studies on the use of picture books for moral education in China. A researcher once used second grade students in an elementary school as the subjects of the study and carried out picture book teaching for fourteen weeks. By 
observing the qualities that the students lacked, the researcher concluded the themes of the picture books. For example, some students were unkind to others, teased their classmates, and even gave them nicknames. In response to this situation, the researcher established the theme of "respect" and "friendship" in teaching, and used picture books with corresponding content as the medium of instruction. In this experiment, the researcher established seven core virtues and developed thematic lessons. At the end of the experiment, it was found that the thematic moral education curriculum with picture books was effective. At the end of the experiment, the researcher asked students to reflect on whether they had been influenced by the picture book lesson and found that they had improved in certain behavioral expressions. The answer was yes. For example, some students will apply the moral ethics of unity and love and respect for others to their lives. Mei Mei and Le Le will take turns teaching Han Han math during recess in hopes of helping her improve her academic performance. Jun Jun learns to ask permission in advance before taking Yue Yue's eraser when he borrows it. The experiment concluded that picture books have a positive and positive impact on the character development of second graders [2].

According to the above-mentioned cognitive characteristics and cases of elementary school students, the author believes that the use of picture books as a medium of moral education in elementary school is highly advantageous. Firstly, the combination of pictures and text in picture books has broken the traditional knowledge inculcation type of education. The vivid pictures can attract children's interest in reading, which is beneficial to children's own emotions into the story context, thus forming a memory point. In daily life, children may imitate the good moral behavior in the picture book stories, thus promoting the achievement of moral education purposes. Secondly, the successful experimental cases have also provided new ideas for China's picture book moral education strategy, that is, to select picture books with specific themes for targeted moral quality education. Moral education in schools requires educators to exert moral influence on the educates in a planned, purposeful and systematic way, which includes the cultivation and education of various moral qualities, such as the cultivation of one's sense of responsibility, patriotic feelings, and the cultivation of mutual help behavior and so on. Therefore, in the selection of picture books, teachers should also fully integrate the students' moral shortcomings and give proper guidance. Step by step, slowly build the bridge of children to sound moral character. Thirdly, as mentioned before, children in the preoptional stage do not yet have perfect abstract thinking skills, and picture books that combine illustrations and text are more suitable for children's understanding of abstract concepts.

\section{A VIRTUOUS CYCLE OF TEACHING AND LEARNING FACILITATED BY PICTURE BOOK TEACHING}

\subsection{The promotion of picture book teaching activities to students' interest in learning}

In a good picture book class, in addition to excellent picture books as teaching materials, teachers also need to carefully design class activities closely related to the content of the picture book, so as to enhance students' interest in learning and enhance their understanding and perception of the curriculum.

For example, the theme of "accept yourself, gain confidence" foreign language picture book I Don't Want Curly Hair, its general content is: a curly-haired girl does not like her own messy curly hair, so she tried every way to make her hair straight. Until one day she met a straight-haired girl, straight-haired girl surprisingly also want curly hair. It dawned on the two girls that their hair wasn't so bad after all. They had a lot of fun designing fun hairstyles for each other. Eventually, they grew to like their hair. Then the teacher can design the lesson to include a group discussion session. After a general introduction to the story, organize a group discussion for students to express their worries and lack of confidence. After talking with the students, they will understand that everyone has their own worries. It is no big deal, and accepting yourself is the path to happiness.

Another example is, the scholars mentioned above used the time of physical exercise class to design a two-person three-legged race when teaching the picture book Swimmy. The class was divided into two groups and competed to see which group reached the finish line first. After the activity, the researcher interviewed the participants. It turned out that everyone was very interested in the game and had a good time [2].

In this way, picture book learning combines the story with students' personal experiences, which can stimulate their emotional experience and recognize the power of self-confidence. Such moral education will drive students' emotional experiences and have a subtle impact on their character building.

\subsection{The promotion of picture book teaching to teachers' development}

The teaching of picture books is different from the teaching of subjects in the traditional sense, there is no specific syllabus, and the teaching methods need to be figured out by teachers little by little. Take Chinese class as an example: the Chinese Curriculum Standards for Compulsory Education (2011 Edition) issued by the Ministry of Education clearly stipulates 10 curriculum objectives and contents, including "Learn Chinese 
Pinyin", "Learn the basic ability of daily oral communication", "cultivate patriotism" and so on. This shows that Chinese class has clear curriculum objectives, curriculum design and assessment standards. As picture books have not become the textbooks stipulated in the curriculum standards, the teaching methods have great flexibility. According to the different themes of the picture book, teachers can design colorful extension activities, including painting, handwork, building blocks, dramatic performances, drawing mind maps, writing stories, and writing letters to the characters in the story. There are many ways of expression in picture books, so teachers of all subjects can participate in teaching [6].

Therefore, it is also a great exercise and improvement for teachers' professionalism. In the process of learning picture books, teachers' guidance and education is a very important part. Some scholars have pointed out that the traditional picture book reading does not meet the needs of children, three-dimensional picture book reading in practice is very popular with children. The three-dimensional picture book reading refers to the process of reading, the adult-child interaction at any time and the freedom of children to share their feelings at any time. After reading, according to the theme of the picture book, the teachers let children to retell, perform, draw, write and through forms to review the picture book. This is in fact an interactive approach to education, where the information is transmitted in both directions. For example, when conducting teaching activities, the teacher is able to directly observe whether the children are having fun reading, whether they have a desire to express themselves, and whether the activity resonates with the children by associating them with their own life experiences. Through the teacher's observation and interaction with students, they continuously adjusted and improved the activities after class to improve the quality and effectiveness of teaching. This is actually a process of teaching reflection, which is very helpful for teachers' own professional growth.

Moreover, in the process of interacting with students, educators listen carefully to students' opinions, respect their ideas, and care for their daily lives. Not only should they educate as educators, but also provide care as caregivers. In such interaction and care, the distance between teachers and students is getting closer and the teacher-student relationship is enhanced. Teachers and students will also get to know each other better and open up their hearts more. This is a great help for teachers to teach and students to do well in school. Teaching will be facilitated by picture book teaching mode, and a virtuous cycle of teaching and learning will be realized.

\section{CONCLUSION}

The new standards for the elementary school character and life curriculum suggested that the content of the curriculum should be extended from textbooks to all topics that are meaningful and interesting to children [7]. Picture books has rich moral and unique moral value, and in the education of excellent picture books, both teachers and students can gain growth. However, since the use of picture book is not yet regulated in China, its moral significance has not yet been fully explored. Educators should pay attention to the value of picture books and inject new vitality into moral education in China.

There are some limitations to this study. Picture books were introduced to China from the West, and if they are to be used as educational materials in China, educators will have to consider the cultural differences between the West and China in the picture books. This essay does not specifically analyze the cultural aspect, but it is a point that must be taken seriously when selecting picture books. Attention upon the misleading nature of cultural differences should be paid specially. In addition, because moral education is complex and long-term, the moral development process of students is influenced by various factors such as school, family and society. Therefore, picture books are worthy of being promoted and practiced as an effective educational tool. However, to achieve the effect of moral education, we need to make efforts and explore new paths.

\section{REFERENCES}

[1] Liu, J. Research on Children's Picture books. Shanghai Normal University, 2010.

[2] Chen, R. Action Research on Character Education Through Picture Books. Nanjing Normal University, 2013.

[3] Wu, N. The Application of Picture books in Foreign Primary and Secondary Education. Foreign Primary and Secondary Education, 2013(5):14.

[4] Lv, H. Research on children's picture book publishing in China based on developmental Psychology. Publication Reference, 2017(08): 56-58.

[5] Naoto, M. My theory of picture books. Guo Wenxia, $\mathrm{Xu}$ Xiaojie. Shanghai: Shanghai People's Art Publishing House, 2009.

[6] Wu, N. Picture Book Reading Course is not A Chinese Course. Jiangsu Education, 2019(57):19-23.

[7] Zhu, Z. Picture books open a window for moral Education. Moral Education of Primary and Secondary Schools,2015(01):41-42+33. 